\title{
Global \& Community Health: The Gorgas experience
}

Joy Zhuo Ding, MD

Neurology ${ }^{\circledR}$ 2019;92:1019-1021. doi:10.1212/WNL.0000000000007542
Correspondence

Dr. Ding

joy.ding@medportal.ca

Picture a different kind of residency experience: living in Peru for 9 weeks to learn about tropical infectious diseases, seeing real patients with leprosy and other tropical neurologic infections, surfing into the sunset on the Pacific Ocean, enjoying some of the world's best ceviche, and becoming lifelong friends with 37 other physicians invested in global health. Then, at the end of it all, obtaining your Diploma of Tropical Medicine and Hygiene to pave a way towards a career in global health neurology.

This encapsulates the Gorgas experience.

The Gorgas Diploma Course in Clinical Tropical Medicine is a 9-week course taught in English for physicians, nurses, and public health professionals. It is a collaborative partnership among the University of Alabama at Birmingham, the Alexander von Humboldt Tropical Medicine Institute, and the Universidad Peruana Cayetano Heredia in Lima, Peru, to fulfill an educational gap for the international medical community seeking intensive clinical tropical medicine exposure with real patients. Cayetano Heredia is the referral center for infectious diseases in Peru, with expertise and subspecializations in leprosy, leishmania, human T-cell lymphotropic virus (HTLV)-1, HIV, and tuberculosis. The tropical medicine unit has 36 inpatient beds, which is where most of the bedside teaching occurs. Consultants from fields such as neurology, dermatology, ophthalmology, and general surgery are called upon for assistance in diagnosis and management. During the Gorgas course, internationally renowned collaborators and researchers also assist with teaching and patient consultations. The course is intensive. There are weekly quizzes, a midterm, and a final examination. Those who successfully pass the final examination receive the Diploma of Tropical Medicine and Hygiene, which is equivalent to the Diploma of Tropical Medicine and Hygiene obtained through the London School or Liverpool, among others. However, what sets the Gorgas course apart from all other diploma courses is the ability to see real patients with tropical infections instead of being limited to lectures, videos, or textbooks.

We spent 7 weeks in Lima, 1 week in Cusco, and 1 week in Iquitos (figure). The days start at 7 AM with a bus ride to the hospital and end at 4 PM with our last lecture. We have a total of 3 hours of lectures spread throughout the day, 2 hours of patient rounds, and 2 hours of laboratory/ small group sessions. Patient rounds are conducted with small groups of 5-6 students, led by a staff physician. The patients are selected from the inpatient wards or invited from all over the country to retrospectively teach us about their disease. We do not know their diagnosis ahead of time. Instead, we are expected to work together to perform a thorough history, examination, and analysis of their associated imaging to come up with a differential diagnosis and preferred diagnosis. After our own attempt at a diagnosis, the final diagnosis is revealed. The staff physician then conducts a brief teaching point about the disease and offers clinical pearls about the differential diagnosis. The patient encounter is completed by reviewing diagnostic testing (such as biopsy, culture, smear) with the pathologist. This complete exercise from clinical presentation to final pathologic diagnosis cements these tropical infectious diseases into memory more than any videos, photographs, or lectures could accomplish. 


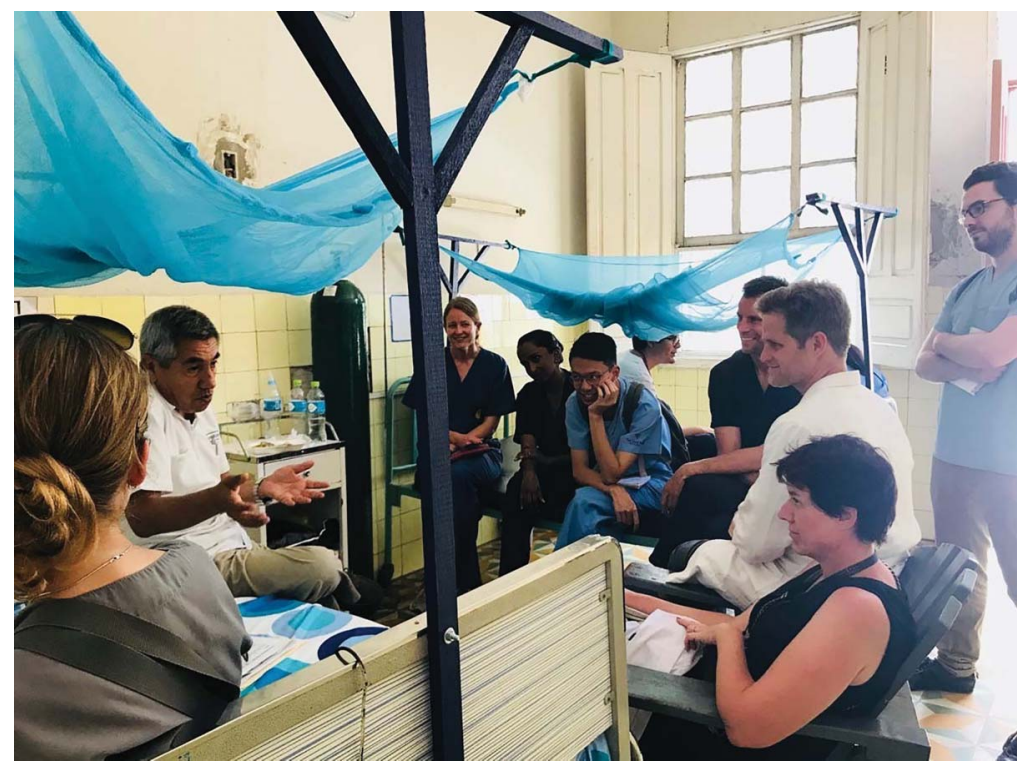

This was our last clinical rounds of the Gorgas course, led by Dr. Pedro Legua, the leprosy specialist.

The course is usually held January to March of each year, with applications opening 15 months beforehand. Applicants are chosen from around the world, though maximum limits are placed on the number of participants from each continent. The application process consists of $\mathrm{CV}$, a personal statement, and 3 letters of reference. Tuition is $\$ 8,600$ USD this year, which includes accommodations and flights to Cusco and Iquitos. Students are responsible for finding accommodations in Lima.

Our class had 38 students from countries including the United States, Canada, United Kingdom, Japan, Germany, Switzerland, Sweden, Singapore, South Africa, Australia, and Papua New Guinea. Participants specialized in the fields of neurology, internal medicine, infectious disease, microbiology, emergency medicine, pediatrics, intensive care, family medicine, obstetrics/gynecology, nursing, and clinical epidemiology. About 30\% were trainees. What bound us together despite our differences in origin, specialty, and career stage was our open-mindedness and passion for providing care in resource-limited settings.

Over the 9-week course, we saw over 130 patients. More than $60 \%$ of these patients manifested some neurologic dysfunction. The most common diseases were HTLV-1 and other opportunistic infections associated with HIV, including toxoplasmosis, tuberculosis meningitis, cryptococcosis, and histoplasmosis.

HTLV-1 is an infection rarely seen in North America. Similar to HIV, HTLV-1 is a retrovirus that infects CD4 T cells. Infection with this virus can result in HTLV-associated myelopathy or tropical spastic paraparesis. Patients present with slowly progressive paraparesis with relative sparing of the arms, marked upper motor neuron signs such as hyperreflexia, clonus, spasticity, and urinary complaints, and eventually become wheelchair-bound over decades. HTLV-1 endemic regions of Peru are often rural and medically underserved, making delays in diagnosis common. For example, we saw an HTLV-1-positive mother of 7 from a rural village who began to have gait troubles at age 18 , but was not diagnosed with HTLV-1 until later in life. Because the virus is transmitted through breast milk, some of her children were also infected.

In addition to viral infections, we also encountered free-living amoebas such as Naegleria fowleri, Acanthamoeba, and Balamuthia mandrillaris. They are single-cell organisms that live in bodies of fresh water and chlorinated swimming pools. They gain entrance into the CNS through the skin or nasal cavities and eventually invade the brain. Patients present with multifocal abscesses, basilar meningitis, or cerebritis with involvement of the optic chiasm and nerves. Diagnosis is based on CSF wet mount to visualize the amoeba, brain biopsy for trophozoites or cysts, or PCR of tissue, which needs to be sent to the Centers for Disease Control and Prevention (CDC). These infections are usually universally fatal. We saw previously healthy children who became acutely ill after vacationing near pools or lakes. Two children had trophozoites visualized in the CSF, but PCR was negative for known species of amoebas. During the course, Cayetano was in the process of working with the CDC to uncover these new species of free-living amoeba.

The Gorgas course can be beneficial to residents, fellows, or practicing neurologists in many ways. For physicians who are interested in global health, inner city, or migrant health work, 
knowledge of tropical infectious diseases is essential. Although we will encounter many infectious diseases as migration increases, most of us will not recognize these treatable infections as our standard medical training does not provide adequate teaching in this area. This 9-week course is an intensive but thorough curriculum, and trainees are armed with a knowledge base and diploma they can continue to build upon. Another major benefit of this course is that it can often be completed as a part of a residency or fellowship elective. Finally, the Gorgas course will not only be a means to obtain the Diploma of Tropical Medicine and Hygiene, but also provide a network of local and international physicians for future collaboration and research.

The best part of Gorgas was not the academic curriculum but the people I met and experiences lived. We continue to be in touch through a WhatsApp group, regularly updating each other on interesting infectious cases we have encountered back in our respective countries or posing a difficult question to the group. This experience reaffirmed my passion for global health and neuroinfectious diseases and has been a small step towards a career in global health neurology.

\section{Acknowledgment}

The author thanks the core Gorgas teaching staff: Drs. German Henostroza, Carlos Seas, Pedro Legua, Martin Montes, and Eduardo Gotuzzo; Karen Luhmann, course coordinator; the medical students; fellow classmates; and the patients.

\section{Study funding}

No targeted funding reported.

\section{Disclosure}

J. Ding reports no disclosures relevant to the manuscript. Go to Neurology.org/ $\mathrm{N}$ for full disclosures.

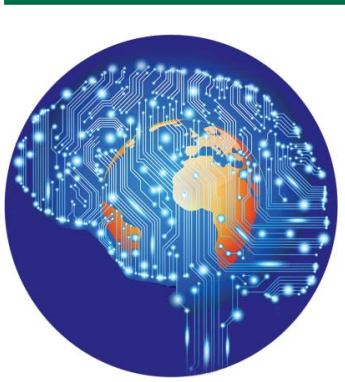

\section{Practice Current: An interactive exchange on controversial topics}

Share your own best practices.

Read commentary with expert opinion.

Explore results on an interactive world map.

\section{Disputes \& Debates: Rapid online correspondence}

The editors encourage comments on recent articles through Disputes \& Debates:

Access an article at Neurology.org/ $N$ and click on "COMMENT" beneath the article header. Responses will be posted within 3 business days.

Before submitting a comment to Disputes \& Debates, remember the following:

- Disputes \& Debates is restricted to comments about studies published in Neurology within the last eight weeks

- Read previously posted comments; redundant comments will not be posted

- Your submission must be 200 words or less and have a maximum of five references; reference one must be the article on which you are commenting

- You can include a maximum of five authors (including yourself) 


\title{
Neurology
}

\author{
Global \& Community Health: The Gorgas experience \\ Joy Zhuo Ding \\ Neurology 2019;92;1019-1021 \\ DOI 10.1212/WNL.0000000000007542
}

This information is current as of May 20, 2019

\section{Updated Information \& Services \\ Subspecialty Collections}

Permissions \& Licensing

Reprints including high resolution figures, can be found at: http://n.neurology.org/content/92/21/1019.full

This article, along with others on similar topics, appears in the following collection(s):

\section{All global neurology}

http://n.neurology.org/cgi/collection/all_global_neurology Poverty-related disease

http://n.neurology.org/cgi/collection/poverty_related_disease

Training-international

http://n.neurology.org/cgi/collection/training_international Underserved populations

http://n.neurology.org/cgi/collection/underserved_populations

Information about reproducing this article in parts (figures,tables) or in its entirety can be found online at:

http://www.neurology.org/about/about_the_journal\#permissions

Information about ordering reprints can be found online:

http://n.neurology.org/subscribers/advertise

Neurology ${ }^{\circledR}$ is the official journal of the American Academy of Neurology. Published continuously since 1951, it is now a weekly with 48 issues per year. Copyright @ 2019 American Academy of Neurology. All rights reserved. Print ISSN: 0028-3878. Online ISSN: 1526-632X.

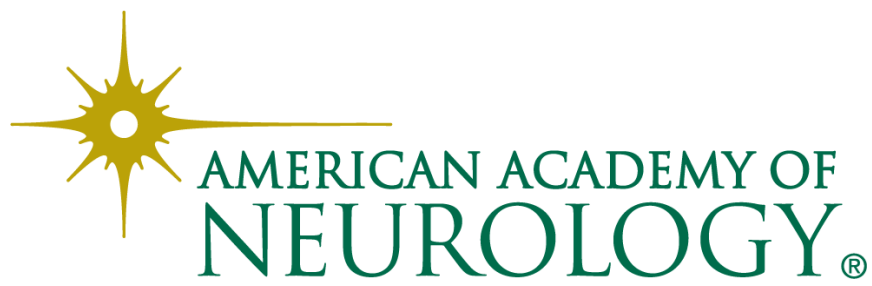

